\title{
PATOGENICIDAD Y RESPUESTA SEROLÓGICA DE LAS TÓRTOLAS (Eupelia cruziana) FRENTE A UN DESAFÍO EXPERIMENTAL CON UN VIRUS DE LA ENFERMEDAD DE NEWCASTLE
}

\author{
Juan Vargas Z. ${ }^{1}$, Mónica Alba Ch. ${ }^{2}$, Eliana Icochea D. ${ }^{2}$, Nieves Sandoval Ch. ${ }^{3}$ y \\ Alberto Manchego S. ${ }^{4}$
}

\section{Abstract}

This study was designed to assess the susceptibility of turtle-doves (Eupelia cruziana) to Newcastle virus. A group of 15 turtle-doves was inoculated with a velogenic viscerotropic strain of the Newcastle virus, and a group of 15 was used as control. Both groups were raised in the same environmental conditions and were fed with similar feeds, but kept separate. Clinical signs and mortality were recorded. Blood samples were tested by the hemaglutination inhibition technique and tissue samples were collected for virus recovery and histological studies. From the inoculated group, 6 birds showed nervous signs like head tremors, neck torsion and uncoordinated movements, and three of them died. Macroscopic lesions were observed on the nervous system. Histological lesions were observed in the brain, and in lungs and tracheal epithelium. An increase in the antibody titers was observed at the $7^{\text {th }}$ day of exposure to Newcastle virus, reaching the highest titers $(\mathrm{PGT}=12.1)$ at the $21^{\text {th }}$ day. Viral recovery was obtained in lung and trachea tissues, and from a cloacal swab from dead birds.

Key words: Newcastle virus, turtle-doves, hemaglutination inhibition technique

\section{RESUMEN}

Con el objetivo de evaluar la susceptibilidad de la Eupelia cruziana (tórtola) al virus de la enfermedad de Newcastle, se inocularon 15 aves adultas con una cepa de virus velogénico viscerotrópico de la enfermedad de Newcastle y 15 fueron usadas como control. Ambos grupos fueron sometidos a similares condiciones ambientales y de alimentación pero en lugares separados. Se llevó un registro de signos clínicos y mortalidad y se tomaron muestras de sangre para la prueba de Inhibición de la Hemaglutinación y muestras de tejidos para evaluación histopatológica y recuperación viral. Seis aves del grupo inoculado presentaron signos clínicos de tipo nervioso (tremores en cabeza, torsión de pescuezo e incoordinación para desplazarse) y tres de éstas murieron. Lesiones macroscópicas y microscópicas fueron observadas en el sistema nervioso y en el análisis histopatológico se observaron lesiones en tráquea y pulmón. Se registró un incremento en los niveles de anticuerpos a partir de los 7 días post-inoculación alcanzando el mayor promedio geométrico de títulos $(\mathrm{PGT}=12.1)$ a los 21 días. Se logró la recuperación viral a partir de pulmón, tráquea e hisopado de cloaca en aves muertas por la enfermedad.

Palabras clave: virus de Newcastle, tórtola, inhibición de la hemaglutinación

\author{
${ }^{1}$ Práctica privada \\ ${ }^{2}$ Laboratorio de Patología Aviar y Producción Avícola, FMV-UNMSM \\ ${ }^{3}$ Laboratorio de Histo-Patología Animal, FMV-UNMSM \\ ${ }^{4}$ Laboratorio de Microbiología y Parasitología Veterinaria, FMV-UNMSM
}




\section{INTRODUCCIÓN}

La enfermedad de Newcastle (ENC), causada por un virus del género Avulavirus (ICTV, 2002), serotipo Paramixovirus Aviar tipo 1 (APMV-1), es uno de los principales patógenos para las aves (Alexander, 1998; King, 1999). Es una enfermedad de distribución mundial y se ha reportado infecciones en más de 240 especies de aves (Alexander, 1998).

La Oficina Internacional de Epizootias (OIE) ha establecido que la ENC representa la enfermedad de mayor riesgo para el intercambio comercial de aves y productos de origen animal (SENASA, 2001). Los signos clínicos asociados con la enfermedad comprenden problemas respiratorios, digestivos, disminución en la postura, depresión, edema de cabeza, signos nerviosos y muerte (Alexander, 1998). La mortalidad y la morbilidad pueden llegar al 100\% (Baez, 1994; Alexander, 2003; Monrroy, 2000).

La Eupelia cruziana (tórtola) pertenece al orden Columbiformes y es la especie con mayor presencia en los alrededores de las instalaciones de granjas avícolas a nivel de la costa, especialmente en Lima; pudiendo constituir un riesgo en la transmisión y diseminación de enfermedades. En un estudio realizado en aves silvestres del orden Columbiformes (Columba livia y Eupelia cruziana) en una zona donde ocurrió un brote de la ENC en pollos de carne, no se encontró presencia de anticuerpos contra este virus a la prueba de Inhibición de la Hemaglutinación (IH) (Carrión, 2000). Con el fin de determinar la susceptibilidad de la Eupelia cruziana a esta enfermedad, se diseñó el presente estudio para evaluar el efecto patogénico y la respuesta serológica frente al desafío experimental con una cepa del virus de la enfermedad de Newcastle (VENC).

\section{Materiales y Métodos}

Se utilizaron 30 tórtolas adultas (Eupelia cruziana) que fueron capturadas en la zona de Lima. Estas aves, luego de un periodo de 2 semanas de adaptación, fueron separadas en dos grupos, control e inoculadas, ubicadas en lugares distantes y sometidas a las mismas condiciones de ambiente y alimentación (maíz refinado y agua ad-libitum).

Las aves fueron inoculadas por instilación nasal y ocular con 100 microlitros de una cepa velogénica viscerotrópica del VENC con una $\mathrm{DLE}_{50}$ de $10^{7} / \mathrm{ml}$. Esta cepa fue aislada de aves de riña afectadas por esta enfermedad.

Se colectaron muestras de sangre de la vena alar de las aves de ambos grupos en el día 0 (antes de la inoculación) y a los 7, 14, 21 y 28 días post-inoculación. El suero obtenido se conservó en congelación hasta su procesamiento mediante la técnica de inhibición de la hemaglutinación (IH).

La observación de signos clínicos se realizó diariamente a partir del día siguiente de la inoculación, clasificándose los signos clínicos en digestivos, respiratorios, y nerviosos. Se llevaron a cabo necropsias a los 7, 14, 21 y 28 días en aves de ambos grupos. Además se necropsiaron las aves que murieron con signos clínicos de la enfermedad. Se tomaron muestras de diferentes órganos en formol al 10\% para el análisis histopatológico y muestras de pulmón y tráquea, e hisopados cloacales para el intento de recuperación viral en huevos embrionados de 9 a 11 días.

Se inoculó $0.3 \mathrm{ml}$ de suspensión de pulmón y tráquea o hisopados de cloaca vía cavidad alantoides en huevos embrionados de 10 días. Se incubaron a $37{ }^{\circ} \mathrm{C}$ durante 7 días, y se observaron diariamente, descartándose los huevos embrionados muertos en las primeras 24 horas. Los embriones muertos se mantuvieron en refrigeración y los sobrevivientes se sacrificaron por enfriamiento. Los fluidos alantoideos de los embriones muertos 


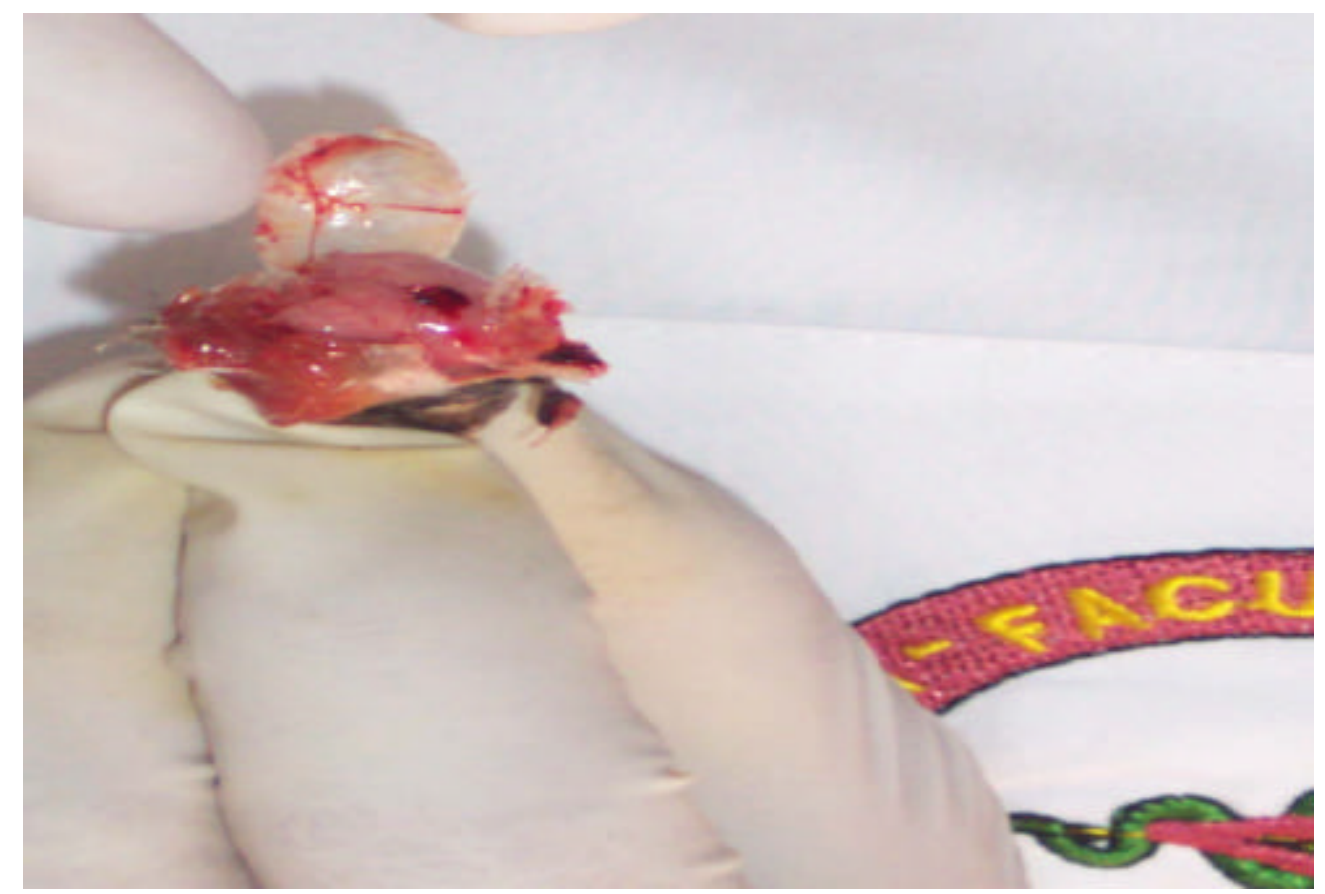

Figura 1. Congestión y hemorragia en cerebro de animales infectados con signos clínicos compatibles con la enfermedad de Newcastle

y sacrificados fueron examinados para determinar la presencia de hemaglutininas virales.

\section{Resultados}

\section{Signos clínicos}

No se observaron signos compatibles con la ENC en el grupo control. En el grupo inoculado se evidenciaron únicamente signos de tipo nervioso en seis (40\%) de las 15 aves a los 14 días post inoculación. De éstas, tres presentaron signos severos muriendo a los 4 días de iniciada la sintomatología, en tanto que las otras tres sobrevivieron. Los signos nerviosos se caracterizaron por tremores en la cabeza, torsión del pescuezo e incoordinación, seguidos por depresión y muerte.

\section{Lesiones macroscópicas y microscópicas}

Se observó congestión y hemorragia en cerebro de animales afectados por la enfer- medad (Fig. 1), y aumento de tamaño en bazo de un ave no afectada. A nivel microscópico se observó degeneración neuronal con hinchazón citoplasmática y picnosis nuclear en cerebro, severo edema perivascular y edema perineuronal, gliosis, satelitosis, y neuronofagia. En el sistema respiratorio se encontraron lesiones como hiperemia en pulmón y pérdida ciliar, atrofia epitelial y exfoliación en tráquea. Se observó además congestión en hígado. Otras lesiones como hemorragia y depleción linfoide en bazo, así como congestión a nivel de pulmón, se encontraron en animales que no presentaron signos clínicos. En ninguna de las aves del grupo control se observaron lesiones asociadas a la ENC (Fig. 2).

\section{Evaluación serológica}

Todas las aves inoculadas con el VENC velogénico viscerotrópico mostraron un nivel creciente de anticuerpos durante el periodo post-inoculación en tanto que las aves del grupo control no seroconvirtieron (Fig. 3). 
a)

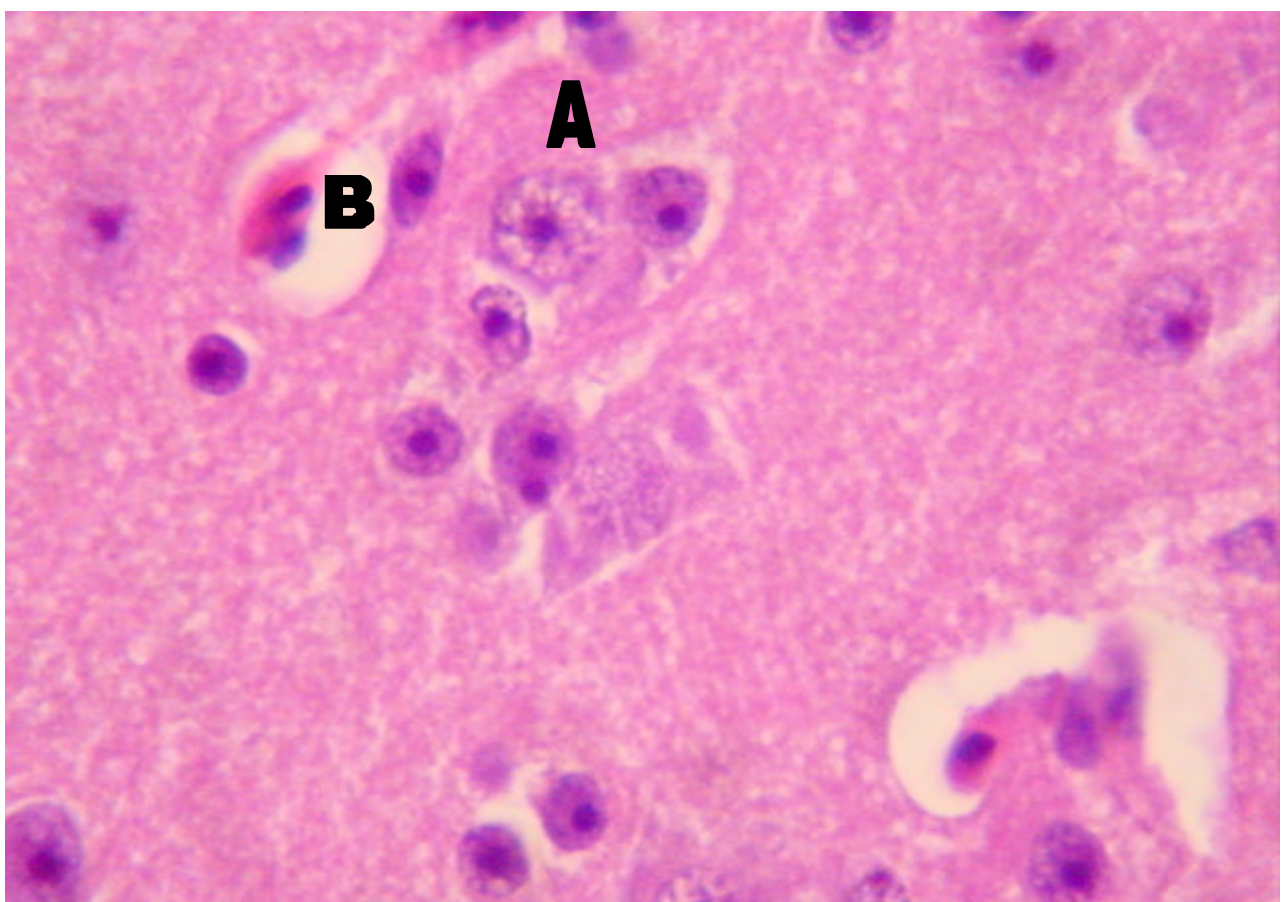

b)

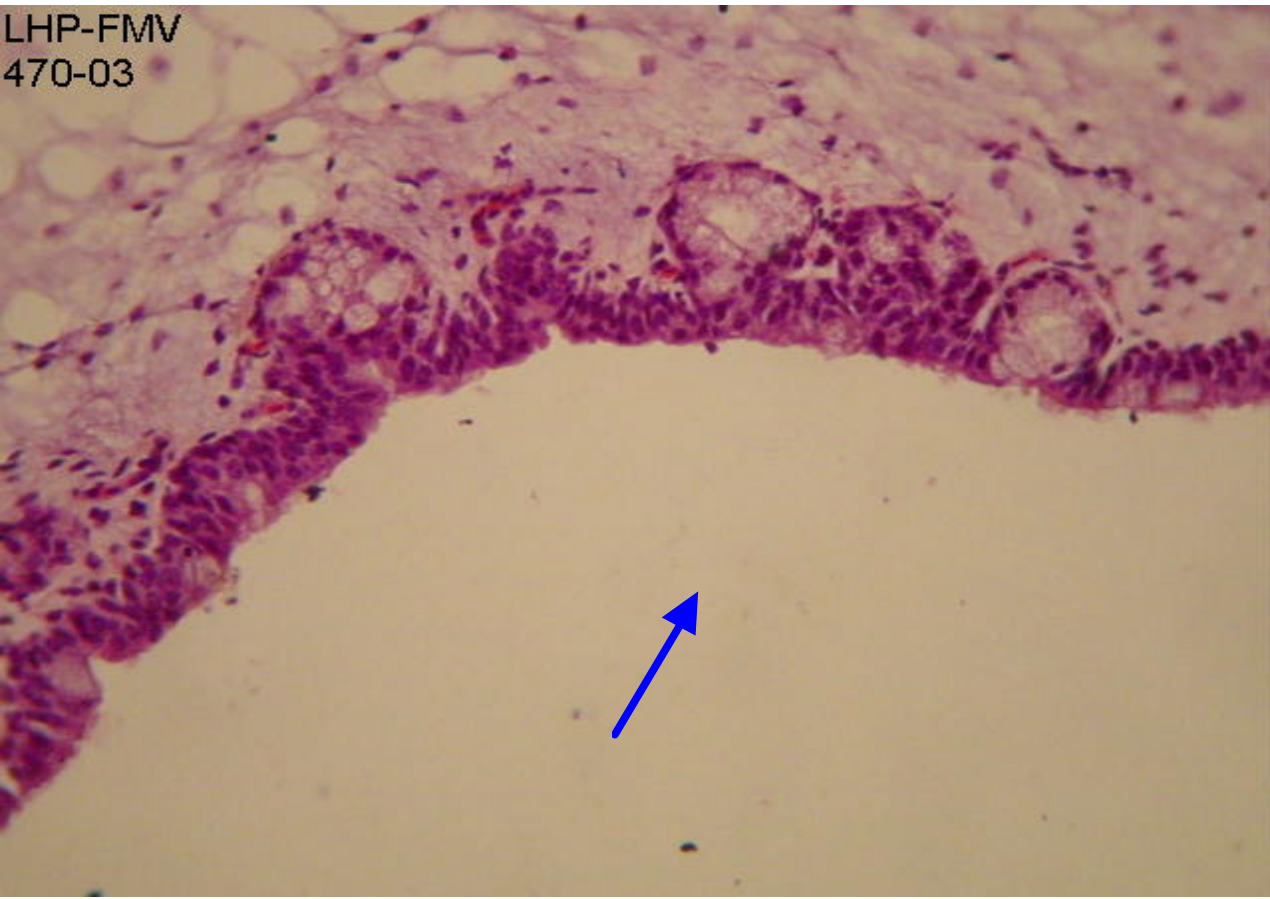

Fig. 2. (a) Corte histopatológico de cerebro de tórtola inoculada con una cepa de virus velogénico viscerotrópico de la ENC. Nótese la degeneración neuronal con hinchazón citoplasmática y picnosis nuclear, además de satelitosis (A) y edema perivascular (B). 40x. Coloración HE. (b) Corte histopatológico de tráquea de tórtola inoculada con virus velogénico viscerotrópico de ENC. Nótese la perdida ciliar de la mucosa (flecha). 40x. Coloración HE. 


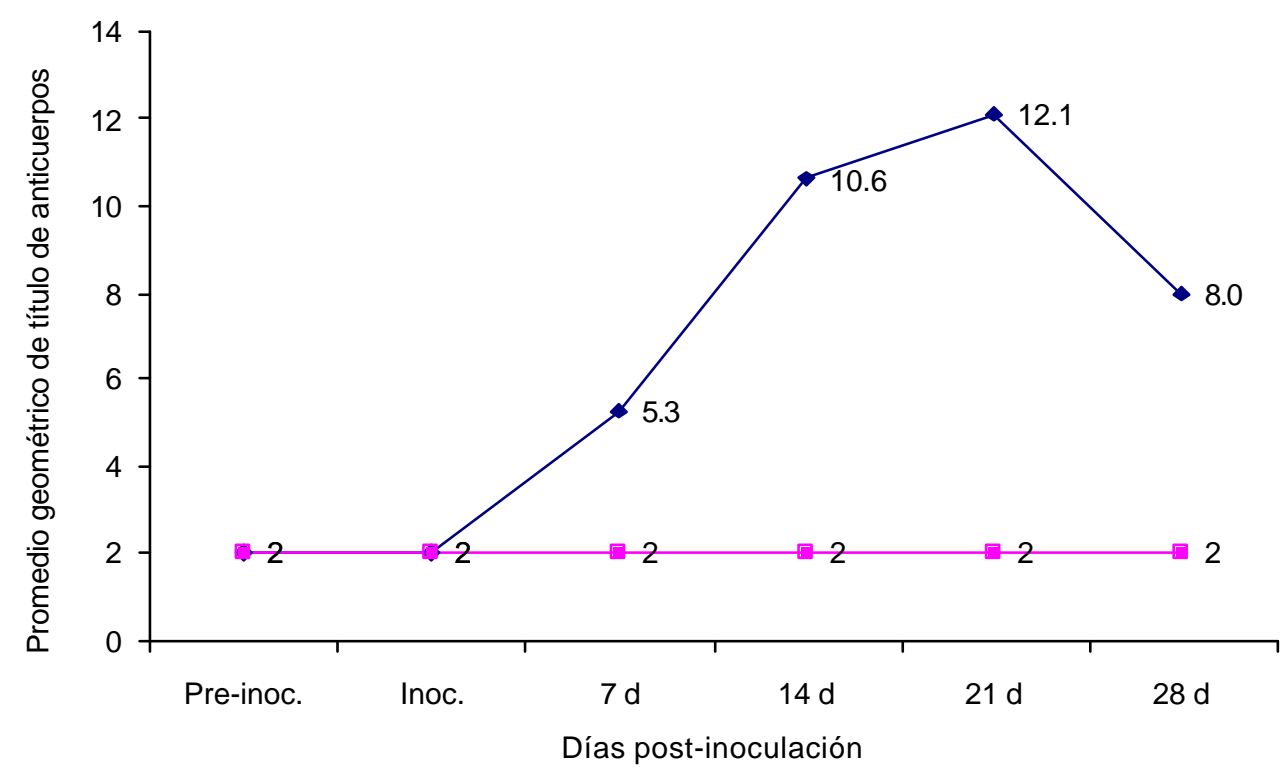

$\multimap$ Inoculadas $\because-$ Control

Fig. 3. Promedio geométrico de títulos de anticuerpos contra un virus velogénico viscerotrópico de ENC por la prueba de IH en tórtolas inoculadas experimentalmente

Cuadro 1. Mortalidad embrionaria y presencia de hemaglutininas virales en huevos embrionados de 10 días e inoculados con suspensiones de pulmón y traquea e hisopado de cloaca, de tórtolas que fueron inoculadas con un virus velogénico viscerotrópico de ENC

\begin{tabular}{cccccc}
\hline $\begin{array}{l}\text { Día de colección } \\
\text { de muestra post- } \\
\text { inoculación }\end{array}$ & $\begin{array}{c}\mathrm{N}^{\mathbf{o}} \text { de huevos embrionados } \\
\text { muertos dentro de } 7 \text { días de } \\
\text { inoculación }\end{array}$ & & \multicolumn{2}{c}{$\begin{array}{c}\text { Prueba de hemaglutinación } \\
\text { (positivos) }\end{array}$} \\
\cline { 2 - 3 } \cline { 5 - 6 } \cline { 5 - 6 } & $\mathrm{HC}^{1}$ & $\mathrm{P} \mathrm{y} \mathrm{T}^{2}$ & & $\mathrm{HC}$ & $\mathrm{P} \mathrm{y} \mathrm{T}$ \\
\hline 7 & $0 / 5$ & $0 / 5$ & & $0 / 5$ & $0 / 5$ \\
14 & $0 / 5$ & $3 / 5$ & & $0 / 5$ & $2 / 5$ \\
18 & $2 / 5$ & $2 / 5$ & & $1 / 5$ & $2 / 5$ \\
21 & $0 / 5$ & $2 / 5$ & & $0 / 5$ & $2 / 5$ \\
28 & $0 / 5$ & $1 / 5$ & & $0 / 5$ & $0 / 5$ \\
\hline
\end{tabular}

${ }_{2}^{1}$ Hisopado de cloaca

${ }^{2}$ Pulmón y tráquea

\section{Recuperación viral}

No se recuperó virus de la ENC en ninguna de las muestras de pulmón o tráquea, ni en los hisopados de cloaca de las aves del grupo control. No obstante, se pudo aislar el virus en los animales afectados con sintomatología nerviosa, tanto de hisopos de cloaca como de muestras de pulmón y tráquea. Los resultados sobre mortalidad embrionaria y prueba de hemaglutinación del líquido alantoideo se observan en el Cuadro 1. 


\section{Discusión}

Los signos clínicos observados en 6 de las $15(40 \%)$ tórtolas inoculadas con un VENC fueron solamente de tipo nervioso, presentando incoordinación al caminar, tremores en la cabeza, cuello torcido, así como postración y muerte en las aves más afectadas. Estos resultados coinciden con la frecuencia de signos clínicos y mortalidad reportados en un estudio realizado en palomas mensajeras, a las que se les inoculó un virus velogénico viscerotrópico de ENC (Erickson et al., 1979).

Las tórtolas del presente estudio no presentaron sintomatología respiratoria, a diferencia de lo encontrado en brotes naturales ocurridos en México en aves exóticas, incluyendo palomas (Estudillo, 1972). Por otro lado, Shivaprasad et al. (1999) menciona que en un brote natural ocurrido en palomas adultas, se aisló el VENC del cerebro, observándose muerte súbita, ocasionales signos respiratorios, diarrea y signos neurológicos. Esas diferencias podrían ser atribuidas a diferencias en el tropismo celular de las cepas de desafío experimental o natural y el tipo de ave afectada.

Las lesiones macroscópicas fueron escasas en los animales afectados, observándose a la necropsia sólo congestión y hemorragia a nivel de cerebro. Estos resultados difieren de lo descrito por Alexander (2003) quien menciona que generalmente las lesiones macroscópicas no son observadas en el sistema nervioso central de aves infectadas con ENC, indiferentemente del patotipo. Se observó también esplenomegalia en una de las dos aves que no enfermaron durante la primera semana post-inoculación, lo que concuerda con lo mencionado por Báez (1994).

El análisis histopatológico a nivel del sistema nervioso mostró lesiones similares a las descritas en pollos de carne afectados por la ENC, observándose gliosis, satelitosis, degeneración neuronal, neuronofagia y edema en el cerebro. Si bien, no se pudo encontrar la presencia de manguitos perivasculares, los cuales son característicos en las infecciones de tipo viral, las otras lesiones mencionadas suelen ser encontradas en este tipo de infecciones. En el sistema respiratorio se observó pérdida ciliar con destrucción de epitelio en tráquea y congestión a nivel de pulmón. Las lesiones antes mencionadas son la consecuencia de la reacción del organismo a una agresión, en este caso ocasionado por la replicación viral posterior al ingreso, vía nasal y ocular. Estas lesiones, aunque con mayor severidad, también son reportadas en pollos con ENC (Alexander, 2003; Ridell, 1996).

Las aves del grupo inoculado seroconviertieron a partir de los 7 días post-inoculación y alcanzaron el mayor nivel de anticuerpos a los 21 días con un promedio geométrico de títulos de 12.1. Estos resultados fueron similares a los encontrados en palomas juveniles inoculadas con un virus velogénico viscerotrópico de ENC que obtuvieron el mayor nivel de anticuerpos a los 21 días, en tanto que palomas adultas lo obtuvieron a los 28 días (Erickson et al., 1979).

El virus fue recuperado únicamente en el grupo inoculado, demostrándose que el grupo control no fue expuesto al virus. En el grupo inoculado se recuperó virus a partir de muestras de pulmón, tráquea e hisopados de cloaca en las aves muertas por la enfermedad mientras que en las aves sacrificadas se recuperó el virus sólo a partir de muestras de pulmón y tráquea. Sin embargo, no se produjo mortalidad ni hemaglutinación positiva en el $100 \%$ de los embriones inoculados con muestras de aves afectadas por la enfermedad como si ocurre en pollos de carne, evidenciando la mayor dificultad para la recuperación viral en tórtolas que en pollos de carne. Estas diferencias evidenciarían una menor susceptibilidad de la especie Eupelia cruziana al virus de la ENC.

\section{Conclusiones}

- La enfermedad de Newcastle logró reproducirse en la especie Eupelia cruziana mediante la infección experi- 
mental con una cepa de virus velogénico viscerotrópico de ENC, induciendo signos clínicos de tipo nervioso en el $40 \%$ y mortalidad del $20 \%$ de las aves.

- Se pudo recuperar el virus a partir de muestras de pulmón y tráquea e hisopados de cloaca de animales infectados.

- El sistema inmunológico competente de las tórtolas indujo la formación de anticuerpos contra el virus velogénico viscerotrópico de ENC.

\section{Limeratura Citada}

1. Alexander, D.J. 1998. Newcastle disease virus and other avian Paramyxoviruses. En: A laboratory manual for the isolation and identification of avian pathogens. $4^{\text {th }}$ ed. Swayne, Chairman, Glisson, Jackwood, Pearson, Beed (eds). p 541-569. University of Pennsylvania, USA.

2. Alexander, D.J. 2003. Newcastle disease and other avian Paramyxoviridae infections. En: Diseases of Poultry. Cap 20. $11^{\text {th }}$ ed. Saif, Barnes, Glisson, Fadly, Mc Dougald, Swayne (eds). p 63-99. Iowa State University, USA.

3. Baez, J. 1994. Enfermedad de Newcastle. En: Patología de las aves. p 15-18. Ed. Trillas. México.

4. Carrión, A. 2000. Prevalencia de anticuerpos contra el virus de la enfermedad de Newcastle en aves silvestres del orden columbiforme en Baños de Boza, distrito de Okayama, provincia de
Huaraz. Tesis de Médico Veterinario. Facultad de Medicina Veterinaria, Univ. Nacional Mayor de San Marcos, Lima. $43 \mathrm{p}$.

5. Erickson, G.A.; Brugh; C.; Beard. 1979. Viscerotropic velogenic Newcastle disease in pigeons: Clinical disease and immunization. Avian Diseases 24: 257-267.

6. Estudillo, J. 1972. A Newcastle disease outbreak in captive exotic birds. En: Proceedings of the Western Poultry Disease Conference. Mexico. 21: 70.

7. ICTV. 2002. Reports of the International Committee on Taxonomy of Viruses. http://www.ictvdb.iacr.ac.uk/Ictv/fr_fstg.htm

8. King, J. 1999. Enfermedad de Newcastle. XVI Congreso Latinoamericano de Avicultura. Lima. p 56-61.

9. Monroy, J. 2000. Epidemiología de la enfermedad de Newcastle velogénica viscerotrópica. En: Enfermedades emergentes: Enfermedad de Newcastle. Facultad de Medicina Veterinaria y Zootecnia, UNAM. México.

10. Ridell, C. 1996. Avian histopathology. $2^{\text {nd }}$ ed. University of Pennsylvania. USA. 234 p.

11. SENASA. 2001. Determinación de anticuerpos de Newcastle en la crianza avícola en el Perú. Mundo Avícola y Porcino 38: 20-21.

12. Shivaprasad, H.; D. Rupiper; P. Woolcock; L. Woods. 1999. An outbreak of Newcastle disease. En: Exotic Pheasants and Doves. Proceedings of the Western Poultry Disease Conference. México. 48: 43. 